\title{
管 \\ ELECTRONIC DATA PROCESSING WITH \\ QUANTITATIVE EVALUATION OF UNIVERSITY QUALITY
}

\author{
Mariya Hristova \\ “Todor Kableshkov" University of Transport, Sofia, Bulgaria \\ OMESTE \\ JEL category: C01, C54, L15
}

\begin{abstract}
This article offers a quantitative assessment of university quality, algorithms for data processing and obtaining a numerical evaluation of its value. Two types of quality are discussed: Class $A$ - of educational objects (subjects, teachers, programs) and class $B$ - of training students as learning outcomes, acquired knowledge, skills, competencies, and values. It is placed emphasized on Class $A$, where assessments of teachers are obtained and similarly, academic leaders can be evaluated, so that they are proportionally stimulated for quality achieved. The summary conclusion is that to achieve objectification, group multi-subject expertise should be applied. Evaluation, which is multifactorial, multisubjective, expert and quantitative (on an interval scale) with the participation of outside experts, requires a substantially complex evaluation system that would be worth only if it is based on modern means of electronic processing and correspondence. The principles of electronic data processing in evaluating the quality of education and university objects (subjects, programs, teachers, etc.) are presented. The article includes designed spreadsheets containing all the attributes: evaluated, assessed, criteria, standards, weight coefficients. Through e-mailing and processing of these tables objective assessments with preserved integrity are obtained. Additional polls are not held. The algorithm of university quality evaluation and algorithm of evaluating a teacher are proposed.
\end{abstract}

Keywords: evaluation of university quality, multi-subject expertise, Objectification of assessments, electronic data processing, algorithm

\section{DEFINITIONS OF QUALITY OF HIGHER EDUCATION}

There are different understandings of quality. A good definition is given in ISO 9001: 2000: "Quality is a set of properties and characteristics of the products or services, which gives them the ability to meet conditional or presumed needs."

Address of the author:

Mariya Petkova Hristova

㫪=" mhristova@vtu.bg
In the context of such an understanding, the quality of a subject is the "degree of compliance of the stated educational goals with their actual achievement" (Biling, 1999).

A classification of definitions of quality is given by Hristova (2007).

The definitions of quality as a degree of compliance do not consider the dynamics of change as a factor influencing on quality.

The definitions of quality as a continuous improvement underestimate the significance of 
standards and requirements to the object of evaluation.

Therefore, the dynamic definitions where quality is examined as a level of compliance in combination with changes of the purpose, which it strives to conform to, are considered to be most suitable. In the paper, the following definition is assumed:
The quality of education is determined by the properties and characteristics of educational product or object (institution, program, subject, etc.), which gives it the ability to satisfy conditional or supposed dynamically changing demands on it. Quality is as better as smaller the difference between the outcomes, on the one hand, and dynamically changing requirements to what is evaluated, on the other hand, is and as more quickly the difference between them is overcome.

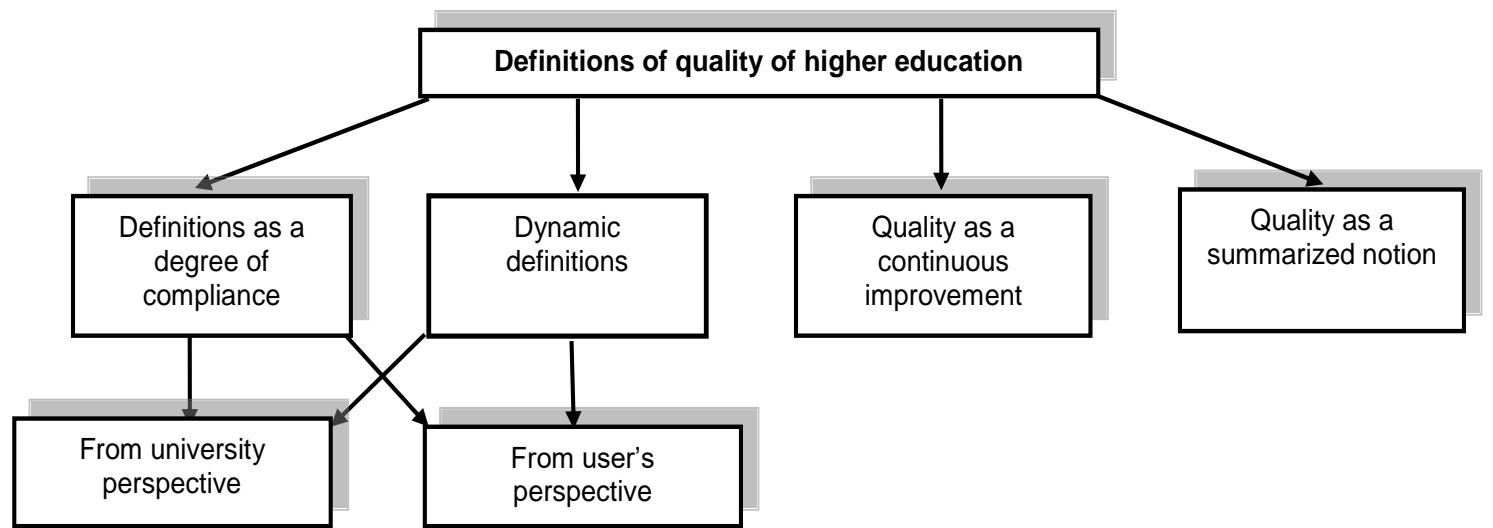

Fig. 1 Classification of definitions of quality

This definition makes possible to give a quantified assessment by comparing the condition of the evaluated object (how things are in reality) with the academic standard, respectively requirements defined (how things should be).

Quality assessment is necessary not only for internal academic purposes but also in regard to the System of Evaluation and Assurance of Quality of teaching and academic staff, which is mandatory under the Higher Education Act, national accreditation, and university ranking system of the Ministry of Education, Youth and Science used to evaluate professional fields at different universities. Its significance has been increasing especially after the amendments to Higher Education Act in Bulgaria in February 2016, under which by $202060 \%$ of university budget funding will have been provided according to the results of national rating.

\section{EUROPEAN DIMENSIONS}

The quality of higher education is one of the values in Bologna Declaration (1998). It is a value that is present in all stages of the Bologna process. Documents of fundamental significance have been adopted as well:
- The European Parliament resolution, which emphasizes that "the quality and relevance of higher education are key conditions for extracting maximum benefit from the intellectual capital of Europe."

- Program for the modernization of higher education systems in Europe. It is where the European Commission accepts quality as a key driver of development and modernization.

- General principles, criteria, and methodology for quality assurance.

- Standards and Guidelines for Quality Assurance in the European Educational Area.

- Recommendations for accreditation agencies to apply the European standards and for universities to implement internal systems of quality management.

\section{CLASSIFICATION OF TYPES OF UNIVERSITY QUALITY ASSESSMENT}

Quality assessment is a condition for its stimulation. To get high quality, it should be encouraged. Subjects "carrying" quality (teachers, students, academic leaders) have to want it and be motivated to achieve it. 
To reward one for quality that he/she has achieved, then first it should be measured and quantified. If the assessment is not quantitative, it cannot be stimulated in proportion. Quantitative assessments must be credible to the extent of being trusted in order to use them to stimulate quality improvement by closing the feedback between quality and its carrier. If the assessment is not adequate, if it cannot be trusted, it creates a sense of injustice - the moral grounds for demotivation of most academic staff. Unfair stimulation should not be applied, it leads to demotivation.

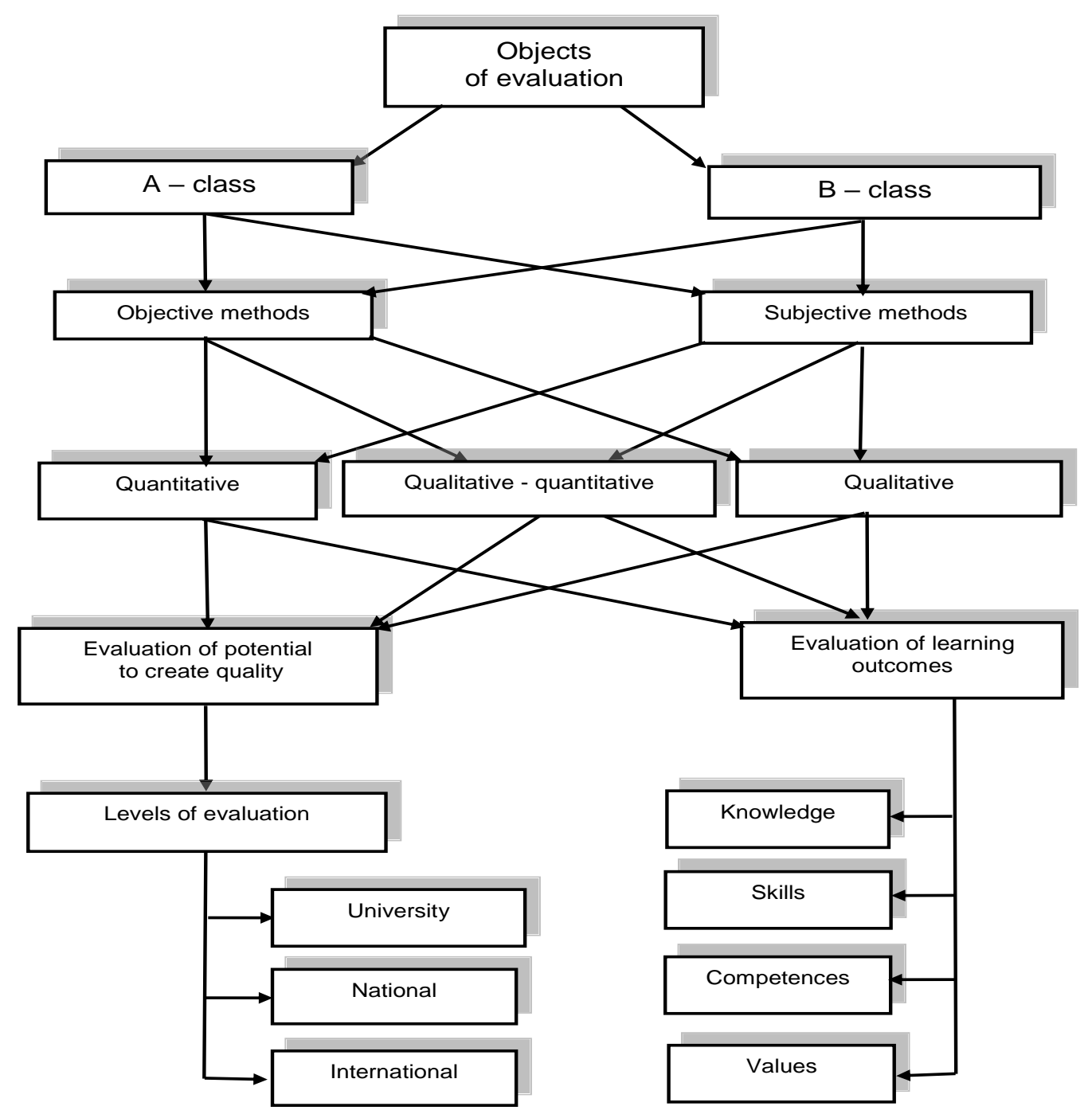

Fig. 2 Classification of quality evaluation types

Depending on what is being evaluated, (Hristova, 2007) has proposed a classification of quality assessment in two branches: A - class, and B class (Fig. 2).

A - class. It assesses the conditions, prerequisites, and potential, which the possibility of the object "to create" quality is judged by, and which, although unequal to implement for all participants, collectively determine the quality related to the corresponding object. The objects evaluated are subject, program, degree, teacher, forms of training.

The fundamental principles of evaluation in the $A$ - class are:

- establishing quality criteria;

- determination of their coefficients of weight;

- measurement of quality indicators.

A - class evaluation is applied also with accreditation. The national evaluation system of Bulgaria has chosen the option where various 
aspects (factors) of training and research processes are assessed.

B - class. The evaluation in this area involves knowledge, skills, competences, and values of students, their ability of career on the labor market, in science and profession, personal fulfillment.

The quality in this class is oriented to outcomes at the exit and is understood as user's satisfaction. Since users in higher education are different (individual, company, state, society) and with different interests, there are different viewpoints on quality.

A well-known way to check the level of training at the exit is the test, of which there are many examples in the world practice and in Bulgaria: tests for general education, tests such as TOEFL, SAT, etc. others. A tool to measure achievements, which is inherent in this class, is the exam. The science of exam and testing has entered in classics of didactics and pedagogy. But university exam today has been gradually losing its original meaning and should be harmonized with the features of the global information society. Knowledge and information are now quickly available but are limitless and cannot be acquired. A university should create abilities in humans to learn and acquire skills to creatively use the knowledge even when it is not his/her knowledge. The task of universities is to teach students to independently learn. These are also the positions, which the requirements to the evaluation of $B$ class should be formulated on.

\subsection{Objectification of assessments}

According to classification in Fig. 2, objective and subjective methods may be applied in both classes of assessments - qualitative and quantitative.

Objective evaluation is formalized control on the compliance with certain standards presented in quantitative metrics. The measurement result is the decision: "is - is not in compliance with". Often, for each parameter, based on objective data and formal methods, it can be established if it is or it is not in compliance with the accepted requirements and standards.

Subjective evaluation is applied when evaluation cannot be formalized. It consists in forming a notion of the expert or group of experts about one or another evaluated indicator of quality and formulation of opinion expressed in numerical or verbal assessment. Benchmarking or comparison lies in the basis of evaluation. The standard, which is compared with, is an established standard. With assessing university objects, such standards are the academic standards of subjects, degrees in professional fields, requirements for teachers set in standards, and also (as much as they exist) the standards for research.

Expert assessments are dependent on the object of evaluation, his/her scientific and professional competence, experience, premeditation and prejudice, emotions, conflict of interest and interpersonal relations. A method to objectify expert assessments provides an introduction of the weight of scores given by each expert. It depends on their awareness and competencies in each of the questions put. The model, which is used to identify the summary evaluation: additive, multiplicative, $\gamma$ - averaging, etc., also influences on objectification. A number of publications are devoted to scientific methods of its definition (Timothy, 2013), (Bowen, 2006), (Berestneva\& Maroukhina\& Sharopin, 2002), etc.

With assessing the achievements of students, the part of an expert is performed by the teacher, examiner. It could be said that the traditional evaluation is subjective, especially in humanities where "digitization" the student's achievements in another way is difficult to make it possible.

It cannot be stated that when the teacher who has read lectures (the holder of the subject) is the examiner at the semester exam, the university, and national standards will be kept. To be closer to the truth, assessments must be given by at least two, one of which may be the holder. The other one necessarily should be an independent expert from another university or a leading specialist in professional business.

Objectification leads to "external testing" famous for decades. Recently, this proven age-old practice of the United Kingdom has given good results in some Bulgarian universities having an impact not only on the adequacy of assessments but also on harmonization with the requirements of the national and European standards and needs of the business.

The summary conclusion is that to achieve objectification, group multi-subject expertise should be applied. During a state exam or thesis 
defense, for example, the State Board of Examiners consists at least of three examiners.

In a summary, the characteristics of evaluation where it is expected to objectify assessments can be reduced to (Bell\& Warwick\& Galbraith 2013), (Ho\& Dey\& Higson, 2006):

- Multi-factor (multi-criteria).

- Multi-subjective - the evaluators are a number of experts (independent, user and self-assessment) with different interests from at least three different countries from different viewpoints and with different viewpoints.

- Expertise - without applying formal method, assessments are given by experts-evaluators based on their own experience, current and objective information according to university data, direct and indirect impressions.

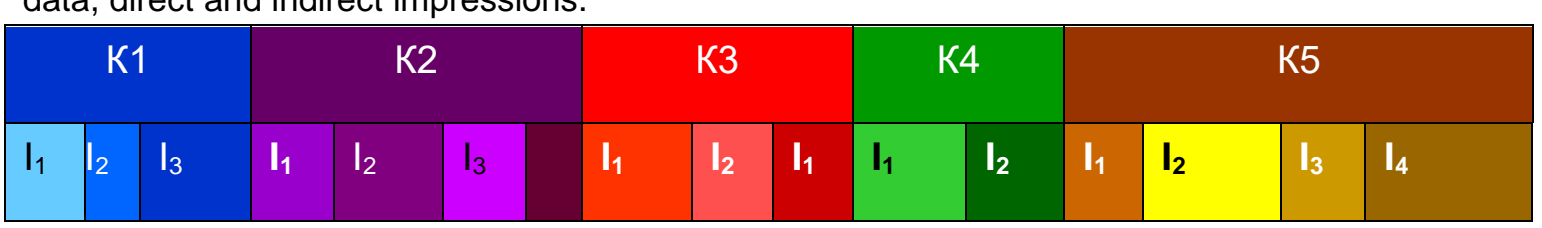

Fig.3 Criteria and indicators

\section{CRITERIA AND INDICATORS FOR EVALUATION OF UNIVERSITY QUALITY}

The indicators for the quality of education are divisions of criteria. The relationship between a criterion and its performance is hierarchical. The criterion is a consolidated component of the complex (aggregate) assessment of quality and is at the "output" of the process. The indicator is a component of the criterion summarizing the raw data of quality and "lies" at its "input". Criteria $\boldsymbol{K}_{\mathbf{i}}$, having indicators $\mathbf{l}_{\mathbf{j}}$, are developed for each evaluated object (Fig. 3).

A number of publications (Shield\&Cartwright, 2015), (Akinbolu\& Cartwright\& Duffy\& Good\& Brown,

2007). present scientific approaches and methods for defining criteria and indicators: stochastic, deterministic, factorial or cluster analyses, multidimensional scaling, etc.

Academic standards, criteria, indicators and sources of quality assessments, including evaluation surveys, are completely interconnected, harmonized and directed to the university mission and priorities, to the National and European qualifications frameworks.

The significance (weight) of criteria in the overall quality assessment is not one and the same and is specified in an expert way. The weight $r<1$ is given by the size of the specific part of the rating scale (range) determined for the criterion. Similarly to criteria, the significance (weight) of indicators in the evaluation of the respective criterion is given by the size of the specific part of the criterial area determined for the indicator.

Weights are determined by the governing body the one that "makes policies" for quality.

The total (global) quality assessment is the sum of scores for all criteria. The scale, which a general evaluation of quality is given by, is a 100-grade interval scale. This type of hierarchical relationships is used in the national criteria system: in accreditation of NEAA and Bulgarian University Ranking System.

\section{COMPLEXITY OF UNIVERSITY EVALUATION SYSTEM}

In a non-formalized area, where assessments are subjective, objectification of results to an extent to trust them as a basis for stimulation can be achieved through a multi-factorial and multisubjective evaluation accompanied with transparency and publicity of assessments. But applied to dozens of programs and degrees, hundreds of subjects, by attracting external evaluators of the same order, the task is complicated and the system becomes difficult to control. When it is very complicated, it might be also inapplicable or inefficient. If it is simplified, for example, to only one evaluator (e.g. Head of Department evaluates in two global criteria: academic activities and research results), such assessment would be unreliable and cannot be used to stimulate quality.

To find reasonable sufficiency is an optimization problem. Several decades ago the search for such 
a solution would not have been appropriate because of the a priori irrationality. Today electronic communication and processing make acceptable even a more complex system.

\section{ELECTRONIC PROCESSING}

\subsection{Database}

Modern universities have uniform electronic systems that manage information processes at the university. Their main functions are to:

- Store the academic information in the form of electronic documents.

- Automate the key information flows and resources.

- Serve administrative activities and learning process, research and development activities.

- Provide comprehensive interconnection of data from different databases.

- Provide access levels from anywhere in the world by Internet and it is regulated according to official powers of authorized persons.

- Integrate the system with national information resources.

For such an electronic system it is not generally difficult to absorb also the electronic data processing of quality evaluation of education and university objects (subject, program, teacher, etc.). The information necessary for evaluating is electronically acquired from all sources and processed only electronically.

\section{Starting databases are:}

- Criteria, indicators, and coefficients of weight addressed to the relevant object and presented in a table (sample Table 1);

- Academic standards by degrees complied with the NQF;

- Educational documentation (qualification characteristics, curriculum, syllabi, theses, etc.);

- Data from other modules of the electronic system necessary to evaluate academic activities, research, and teachers;

- Decisions of the governing bodies that have attitude to evaluation: proved evaluated objects, evaluators, coefficients of weight, etc.;

- Documented learning outcomes and success of students and doctoral students;
- Other documents.

Data access to the system is regulated: of evaluators - single, of authorized officials - for a certain period and under the supervision of the administrative offices.

\subsection{Consultation with evaluators (experts)}

The consultation about the quality of a program, subject, teacher, etc. is made with unified electronic evaluation tables relevant to the object evaluated. Table 1 presents a sample of an evaluation table containing:

- criteria $K_{i}$ and their coefficients of weight $r_{i}$

$$
(i=\overline{1, n}), \sum_{\forall j} r_{j}=1 \text {; }
$$

- indicators $I_{i j}$ and their coefficients of weight

$$
r_{i j}, \sum_{\forall j} r_{i j}=1 \text {; }
$$

- evaluators where $k$ is the next evaluator (expert);

- values of coefficients of the weight $e_{i j k}$ of each evaluator $\mathrm{k}$, for each indicator $I_{i j}$.

Correspondence with evaluators is electronic, tables are exchanged. Other surveys are not used. In the tables received, the experts fill in their assessments for each indicator in the empty fields (of red background). The tables completed in this way are returned electronically where they have been received from. When a coefficient of weight is not specified for the corresponding indicator, it means that the expert does not assess this indicator. The relevant box "Assessor-indicator" in the evaluation table, where the coefficient of weight is written, is empty in these cases. The authorized body has decided that the expert has no competence in the issue or in presumption is non-objective, directly interested in evaluation. When in the process of evaluating any of the assessors decides that he/she has no competence, he/she may omit this assessment.

\subsection{Algorithm of data processing}

Fig. 4 presents an algorithm for data processing with quantitative assessment of quality.

The algorithm of computing the evaluation table automatically reduces other coefficients of 
weighting, so that their sum is kept to be one: $\sum_{\forall j} r_{j}=1$.

For this purpose they are recalculated by the formula:

$$
e_{c i}=\frac{e_{t i}}{1-\sum e_{t r}}
$$

where:

$e_{t i}{ }^{-}$table values of weightings where assessments are given;

$e_{t r}$ - values of weightings where there is the refusal of assessment;

$e_{c i}$ - newly corrected values of weightings where assessments are given.
Fig. 5 presents an algorithm for evaluating a teacher. The tables with criteria and indicators for teachers with academic ranks and those who do not have such ranks are different due to different powers and responsibilities of the two classes of academic staff. It is assumed that there are minimum requirements in the scoring system (e.g. 15 points for teaching and 10 points for research), which each teacher must necessarily cover in order to be assessed and attested by the system examined.

There are separate thresholds for teaching and research. The algorithm is used first to check teaching and then research and results applying criterial evaluation tables of the type of Table 1.

These algorithms already operate systems to quantification at some Bulgarian universities.

Table 1 Evaluation table

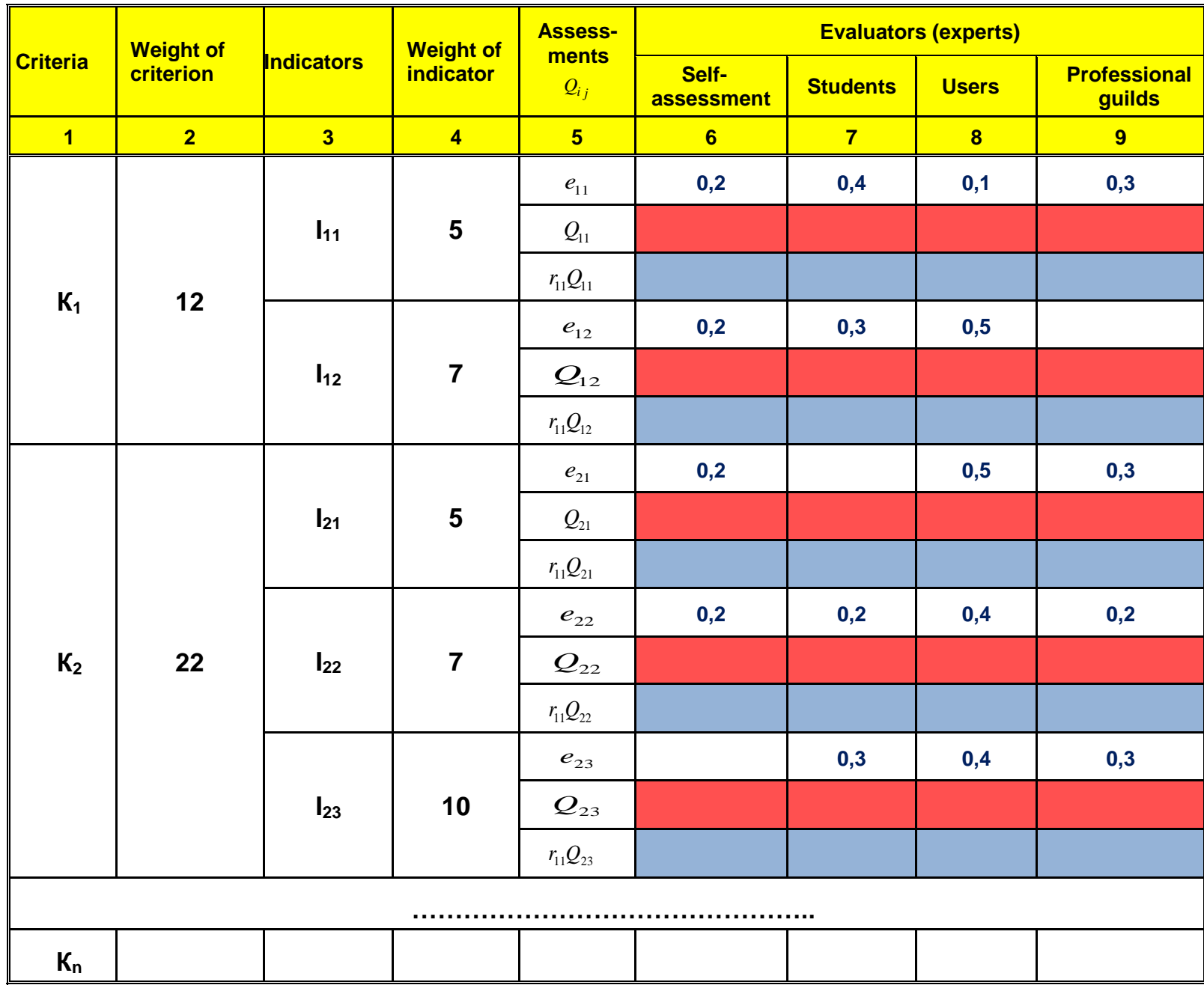




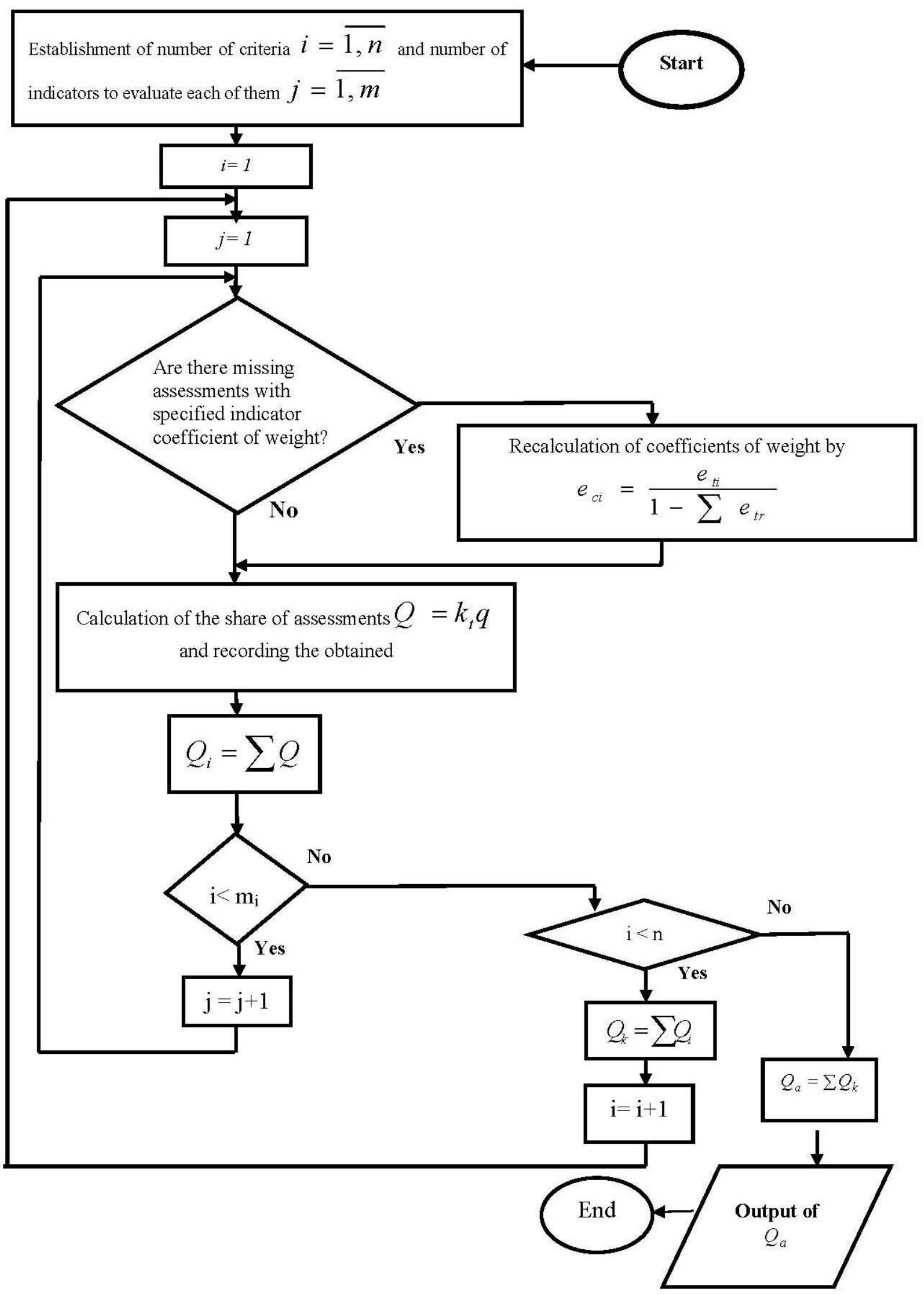

Fig. 4 Algorithm of university quality evaluation 


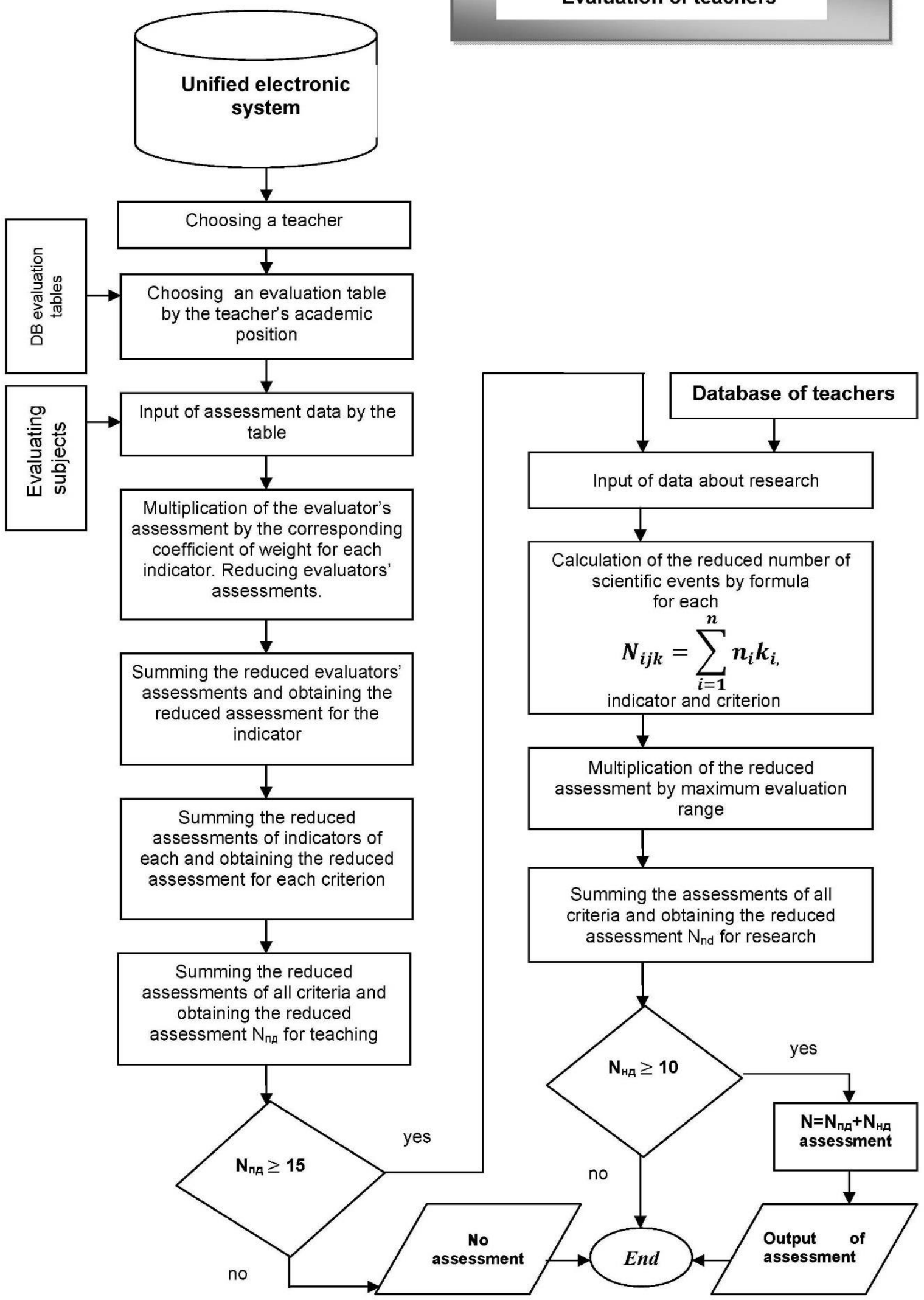

Fig. 5 Evaluation of teachers 


\section{CONCLUSIONS}

The paper has proposed approaches, methods, and algorithms for quantitative (numerical) assessment of the quality of university objects and learning outcomes at the university exit. It is emphasized on the evaluation of teachers who must be motivated to achieve high quality by this system. University management presumably provides a system of proportional stimulation of the academic staff.

By e-mails, e-consultation, and the proposed processing methods it is possible to overcome the complexity of the evaluation system, which otherwise (with conventional technologies) is inapplicable. Accuracy and authenticity are achieved. Data integrity and assessments are stored. Time and resources are saved.

\section{WORKS CITED}

Billing, D. (1999) Proposal for guidelines at the national level quality assurance of higher education Project Manager Phare № BG 9605.01.001

Hristova, M., (2007) Quantitative Methods of Evaluation and Quality Management of Education at Universities, dissertations for the degree of "Doctor"

Bologna Process: http://www.bologna-bergen2005.no/

Timothy T., (2013), Handbook of quantitative methods for educational research, Rotterdam : Sense Publishers, University of Auckland, New Zealand

Bowen G. A., (2006), Combining Qualitative and Quantitative Method for Evaluation, www.wordpress.com/tag/evaluation-tools

Berestneva, O.G., Maroukhina, O.V., Sharopin, K.A., (2002) Evaluation of quality education on the basis of modern information technologies. IEEE International Conference on Artificial Intelligence Systems ICAIS 2002, pp. 441-443

Ho, W., P. K. Dey, H. E. Higson, (2006), Multiple-criteria decision-making techniques in higher education, International Journal of Educational Management, (20), 5, p.319- 337

Bell G., J. Warwick, P. Galbraith, 2013, Higher Education Management and Operational Research: Demonstrating New Practices and Metaphors, Springer Science \& Business Media,

Akinbolu, J., J. Duffy, F. Good, A. Brown, (2007) Review of performance indicators - Consultation to inform the review. The Quality Assurance Agency for Higher Education,

Shiel G., F. Cartwright (2015), Analyzing data from a national assessment of educational achievement Washington, DC : World Bank Group,

ENQA. (2015). Standards and Guidelines for Quality Assurance in the European Higher Education Area (ESG). Retrieved from European Association for Quality Assurance in Higher Education (ENQA): http://www.enqa.eu/wp-content/uploads/2015/11/ESG_2015.pdf

Received for publication: 14.02 .2016

Revision received: $\quad 13.05 .2016$

Accepted for publication: 21.05.2016

\section{How to cite this article?}

Style - APA Sixth Edition:

Hristova, M. (2017, July 15). Electronic data processing with quantitative evaluation of university quality. (Z. Čekerevac, Ed.) MEST Journal, 5(2), 47-57. doi:10.12709/mest.05.05.02.05 
Style - Chicago Sixteenth Edition:

Hristova, Mariya. "Electronic data processing with quantitative evaluation of university quality." Edited by Zoran Čekerevac. MEST Journal (MESTE) 5, no. 2 (July 2017): 47-57.

Style - GOST Name Sort:

Hristova Mariya Electronic data processing with quantitative evaluation of university quality [Journal] // MEST Journal / ed. Čekerevac Zoran. - Toronto - Belgrade : MESTE, July 15, 2017. - 2 : Vol. 5. - pp. 47-57.

Style - Harvard Anglia:

Hristova, M., 2017. Electronic data processing with quantitative evaluation of university quality. MEST Journal, 15 July, 5(2), pp. 47-57.

Style - ISO 690 Numerical Reference:

Electronic data processing with quantitative evaluation of university quality. Hristova, Mariya. [ed.] Zoran Čekerevac. 2, Toronto - Belgrade : MESTE, July 15, 2017, MEST Journal, Vol. 5, pp. 47-57. 